\title{
Thickness Effects on Fatigue Strength of Plates with Semi-elliptical Side Notches and Weld Joints
}

\author{
by S. M. Ikhtiar Mahmud*, Student Member Yoichi Sumi*, Member
}

\begin{abstract}
Summary
Fracture accidents are often caused by fatigue, and these fractures start from the sites of structural discontinuities such as notches, holes, sharp corners, and weld defects which may induce the considerable local stress concentrations. In order to investigate the effects of plate thickness on fatigue strength, semi-elliptical side notches in plates and two types of welded joints of different plate thickness are studied in the present paper. A $n$ empirical formula is used to calculate the stress intensity factors of semi-elliptical side notches in plates so that the thickness effect on fatigue strength can easily been investigated for a variety of geometrical parameters. In the welded joints combined analytical and numerical calculation is performed for the evaluation of stress intensity factors of shallow cracks, and the rest of the calculations are carried out by the finite element method. From this study, the transition point, at which the magnitude of stress intensity factor is reversed has been identified, and the results are contrasted with the $1 / 4$ power law based on the S-N approach.
\end{abstract}

\section{INTRODUCTION}

It is well known that one of the major causes of structural failure is fatigue. Fatigue cracks are often observed at the stress concentrated region of the notches and weld toe. The weld defects such as undercut, porosity, lack of fusion, slag inclusion, incomplete weld root penetration and misalignment may induce fatigue cracks which may lead to a possible structural failure.

Fukuoka and Mochizuki ${ }^{1)}$ studied the effect of plate thickness on fatigue strength considering doubling plates and gusset plates. They investigated the thickness correction exponent of various welded joints and showed that the thickness correction exponent is varied for different joints.

Gurney ${ }^{2,3)}$ stated that thickness effect could be demonstrated using both fracture mechanics theory and experimental work. He pointed out that plate thickness was likely to be a relevant variable for fatigue strength under bending stresses and the effect of plate thickness on fatigue strength could be significant.

Recently, the International Association of Classification Societies (IACS $)^{4,5)}$ developed the Common Structural Rules (CSR) for bulk carriers and tankers, in which the thickness correction factor is taken into account for the assessment of fatigue strength. The thickness correction factor is taken as $k=$ 0.25 , regardless of the types of the welded joints.

The aim of the present study is to investigate the effects of plate thickness on fatigue strength considering semi-elliptical side notches in plates and two types of welded joints. Numerical computations have been carried out based on 2D finite element method.

\footnotetext{
* Y okohama N ational University

Received 21st May 2011
}

\section{ANALYSIS}

\subsection{C alculation of fatigue life 2.1.1 S-N approach}

Gurney ${ }^{7)}$ proposed an empirical thickness correction formula by using S-N data for plate welds and for tubular joints covering the range of plate thickness up to $50 \mathrm{~mm}$. The proposed formula of thickness correction for fatigue strength ;

$$
S=S_{B}\left(t_{B} / t\right)^{0.25}
$$

where $S_{B}$ is the fatigue strength for a reference plate thickness, $t_{B}$ and $S$ is the fatigue strength for a plate thickness, $t$, under consideration. Assuming that the exponent of the S-N curve is 3 , the corresponding thickness correction for fatigue life is;

$$
N=N_{B}\left(t_{B} / t\right)^{0.75}
$$

where $N_{B}$ is the fatigue life for a reference plate thickness, and $N$ is the fatigue life for a plate thickness under consideration.

\subsubsection{F racture M echanics approach}

To calculate the fatigue crack propagation life, the equation of Paris is usually employed, in which the fatigue crack propagation can be calculated by;

$$
\frac{d a}{d N}=\left\{\begin{array}{lll}
C\left(\Delta K^{m}-\Delta K_{t h}{ }^{m}\right) & \text { for } & \Delta K>\Delta K_{t h} \\
0 & \text { for } & \Delta K \leq \Delta K_{t h}
\end{array}\right.
$$

where $\mathrm{d} a / \mathrm{d} N$ is the crack growth rate per cycle, $C$ and $m$ are material constants, $\Delta K$, is the stress intensity range, $\Delta K_{\text {th }}$ is the threshold stress intensity range, $a$ is the crack length and $N$ is the 
number of cycle. The relationship between the crack length, $a$, and the repeated load cycle $\mathrm{N}$ is obtained by;

$$
N=\int_{a_{0}}^{a_{f}} \frac{d a}{C\left(\Delta K^{m}-\Delta K_{t h}{ }^{m}\right)}
$$

where $a_{0}$ and $a_{f}$ are the initial and final crack lengths, respectively. It should be noted that the effect of the thickness is implicitly involved in the calculation of stress intensity range, $\Delta K$, of the problem. The material constant, $C=2.60 \times 10^{-11}, m=2.75$, threshold stress intensity range, $\Delta K_{\text {th }}=2.00 \mathrm{MPa} \sqrt{\mathrm{m}}$ are assumed for the calculation of fatigue life.

\subsection{Stress intensity factors of a crack emanating from semi-elliptical side notches in plates}

In order to estimate the effect of plate thickness of fatigue crack propagation, we first consider a simple problem of a crack emanating from a semi-elliptical notch as illustrated in Fig.1, where the solution of the stress intensity factor is given by an empirical formula ${ }^{8)}$.

\subsubsection{Specimen modelling}

Figure 1 schematically illustrate the plate with semi-elliptical side notches of depth, $d=5.0 \mathrm{~mm}$ and radius of curvature $\rho$. Cracks of length, $a$ emanate symmetrically from these notch roots. $2 l$ and $2 w$ are the length and width of the plate and the length-width ratio is assumed, $l / w=3.0$. The plate is subjected to uniform tensile stress, $\sigma_{0}$, applied at both ends of the specimens.

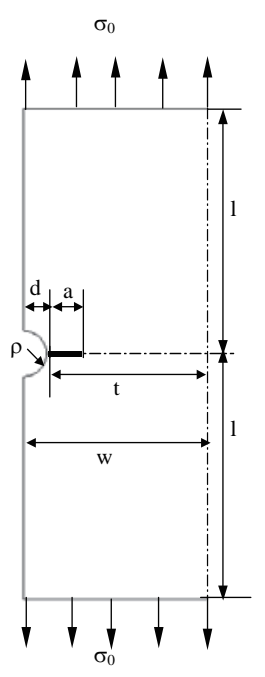

Fig. 1 Geometry of rectangular plate with a semi-elliptical notch (half body is illustrated due to the symmetry)

\subsubsection{Stress concentration factor}

Every discontinuity forms an interruption of the load path, therefore it deviates the load-flow lines and, hence, causes a stress concentration. Stress concentration factor, $k_{t}$ is defined by ${ }^{8)}$;

$$
k_{t}=\frac{\sigma_{\max }}{\sigma_{\text {net }}}=s \frac{t}{t+d}
$$

where

$$
\begin{aligned}
& \sigma_{\text {net }}=\sigma_{0} \times w /(w-d) \\
& \sigma_{\max }=s \sigma_{0} \\
& t=w-d \\
& s=\alpha[1+2 \sqrt{(d / \rho)}] \\
& \alpha=\{1.122-0.122 \exp [-0.2 \sqrt{(d / \rho)}]\}\left[1.0+0.8(d / w)^{4}\right]
\end{aligned}
$$

In the above Equations, $\sigma_{\max }$ is the maximum stress, $\sigma_{\text {net }}$ is the net stress, $d$ is the depth of the notch, and $w$ is the half width of the plate.

\subsubsection{Stress intensity factor}

For shallow cracks, the stress intensity factors are determined with the formula of $\mathrm{K}_{\text {oiter }}{ }^{9}$ by using the maximum stress and its gradient at the notch root in an intact plate. We shall employ the empirical formula given by $Y$ amamoto et al. ${ }^{8}$, which is based on the analytical calculation for the shallow cracks combined with the finite element calculations for deeper cracks.

\subsection{Stress intensity factors of butt and fillet welds}

\subsubsection{Specimen modelling}

Figures 2 and 3 schematically illustrates the specimens with a small undercut for the butt and fillet welds, respectively. In the butt weld, plates of thickness, $t$, are jointed together with groove angle, $\theta=60^{\circ}$, weld reinforcement, $h=4.0 \mathrm{~mm}$, and breadth of the bead, $b=25.4 \mathrm{~mm}$. The semi-circular undercut is located at weld toe, with its depth, $d=1 \mathrm{~mm}$, and the radius of curvature, $\rho$ $=1 \mathrm{~mm}$.

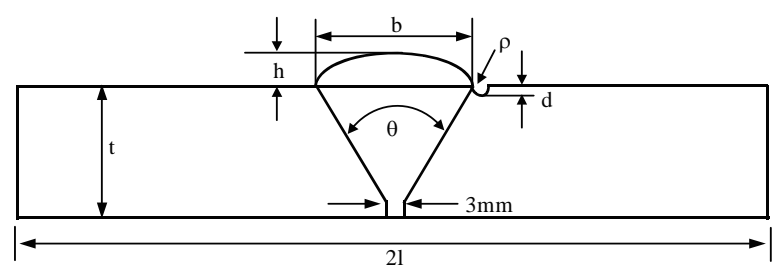

Fig. 2 Geometry of butt weld

In the fillet weld, the attachment is perpendicular to the main plate and the gap between main plate and the attached plate is $0.01 \mathrm{~mm}$, the height of the attachment, $h=40 \mathrm{~mm}$, the thickness of the attachment, $t_{a}=10 \mathrm{~mm}$, the leg length of the fillet weld, $l_{l}=l_{2}$ $=6 \mathrm{~mm}$, and the depth of the undercut, $d=1 \mathrm{~mm}$. Also, the semicircular $(\rho=1 \mathrm{~mm})$ shape is assumed for the undercut. The initial crack is located at the root of the undercut with its length, $a$ $=0.05 \mathrm{~mm}$.

In order to examine the thickness effect, similar types of butt and fillet weld specimen without considering undercut at weld toe have been taken into account, keeping other weld parameters unchanged. The uniform tensile stress is applied at both ends of the specimens for the butt and fillet weld joints. 


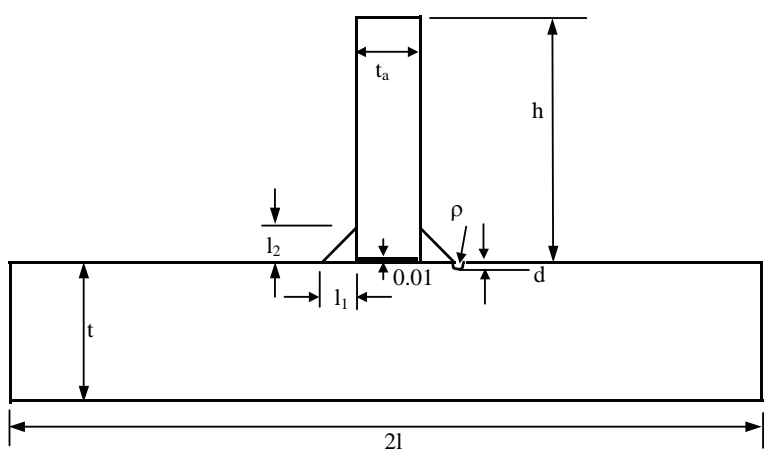

Fig. 3 Geometry of fillet weld

\subsubsection{Finite E lement Analysis}

In order to calculate the stress intensity factor, finite element analyses are carried out by using the finite element code, MSC Patran/Nastran. In Figs. 4 and 5 mesh subdivision near the undercut at weld toe are shown for butt and fillet welds, respectively. In Fig. 6 mesh subdivision at crack tip is shown for the butt weld, where the mid-side nodes of the 8-node quadrilateral elements surrounding the crack tip are moved to the quarter points so as to include the stress singularities at the crack tip.

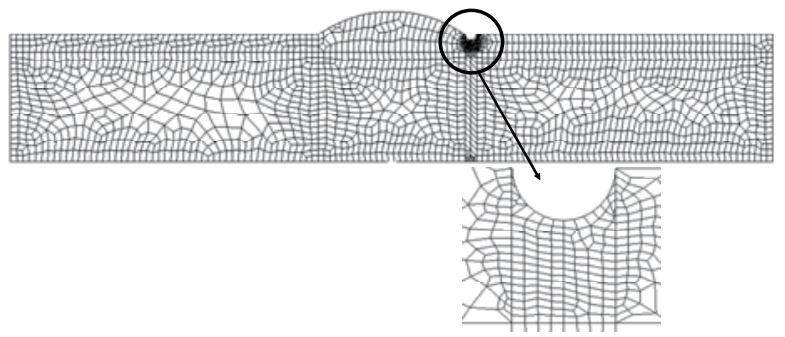

Fig. 4 M esh subdivision of butt weld joint with undercut

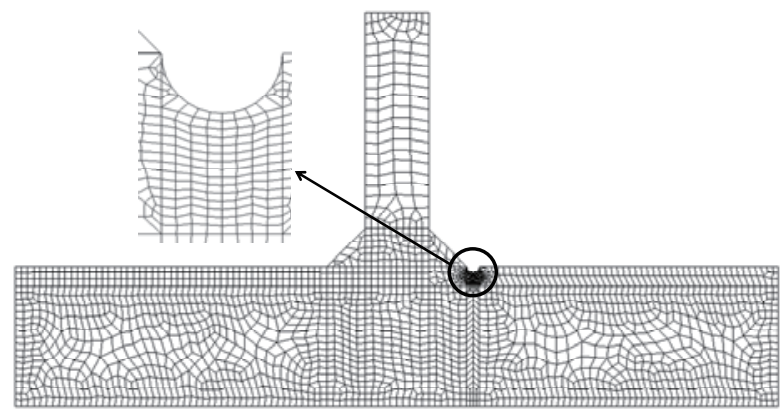

Fig. 5 M esh subdivision of fillet weld joint with undercut

The stress intensity factor is calculated by the following Equation.

$$
K_{I}=\frac{2 G}{\kappa+1} \sqrt{\frac{2 \pi}{L}}\left(v_{2}-v_{1}\right)
$$

$$
\begin{aligned}
& G=\frac{E}{2(1+v)} \\
& \kappa=3-4 v
\end{aligned}
$$

where $G$ is the shear modulus, $E(=206 \mathrm{GPa}$ ) is the modulus of elasticity, $v(=0.3)$ is the Poisons ratio, $L$ is the length of quarter point element and $v$ is the crack opening displacement at the quarter point node.

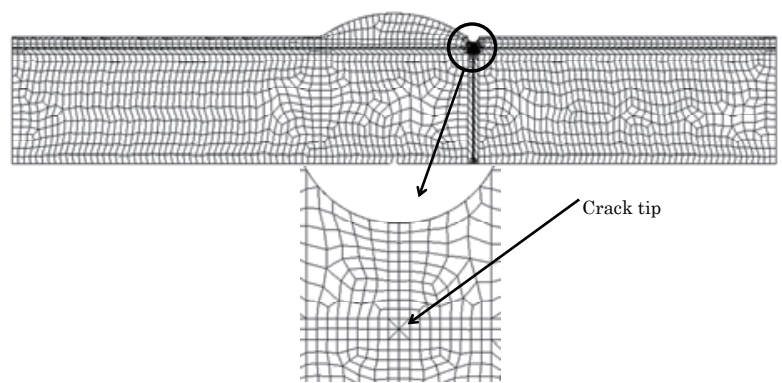

Fig. 6 M esh subdivision of a crack emanating from the butt weld joint

\subsubsection{Stress intensity factor for very shallow cracks at the root} of undercut

In order to circumvent the tedious finite element calculations for very shallow cracks at the notch root, we shall utilize the solution of an edge crack in an semi-infinite plate, in which a maximum tensile stress, $\sigma_{\max }$, with a negative stress gradient, $g$, is acting in an intact plate (see Fig. 7).

The stress distribution can be approximated by,

$$
\sigma_{y}(x)=\sigma_{\max }+g x
$$

where

$$
g \equiv\left(\frac{\partial \sigma_{y}}{\partial x}\right)_{x=0}<0
$$

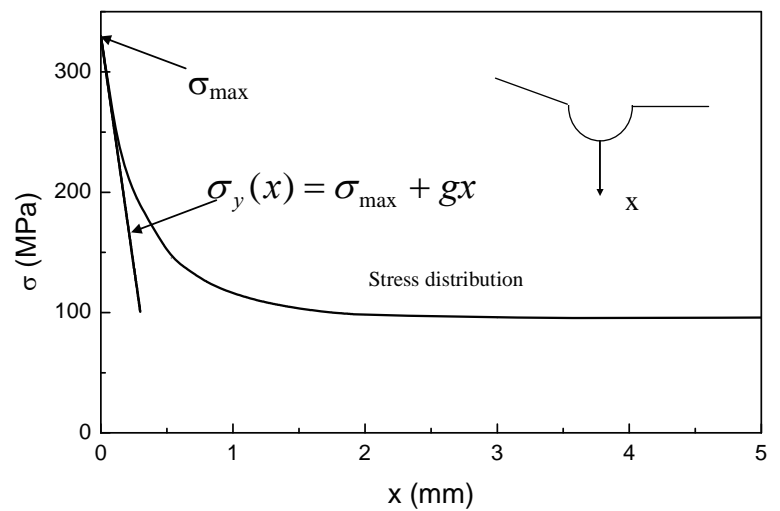

Fig. 7 Stress distribution at the notch root

The stress intensity factor of a crack with its length, $a$, can be 
estimated by ${ }^{9}$ ),

$$
K_{I}=\left(1.122 \sigma_{\max }+0.68 \lg a\right) \sqrt{\pi a}
$$

Having calculated the maximum stress value and its gradient, we shall use Eqn. (10) for the evaluation of the stress intensity factors of shallow cracks at the notch root.

\section{RESULTS AND DISC USSION}

\subsection{Plates with semi-elliptical side notches}

In order to investigate the effect of plate thickness on fatigue strength of plates with semi-elliptical side notches, calculations are carried out by using empirical formula for five different thicknesses of plates $(t=10,22,30,40$, and $50 \mathrm{~mm})$.

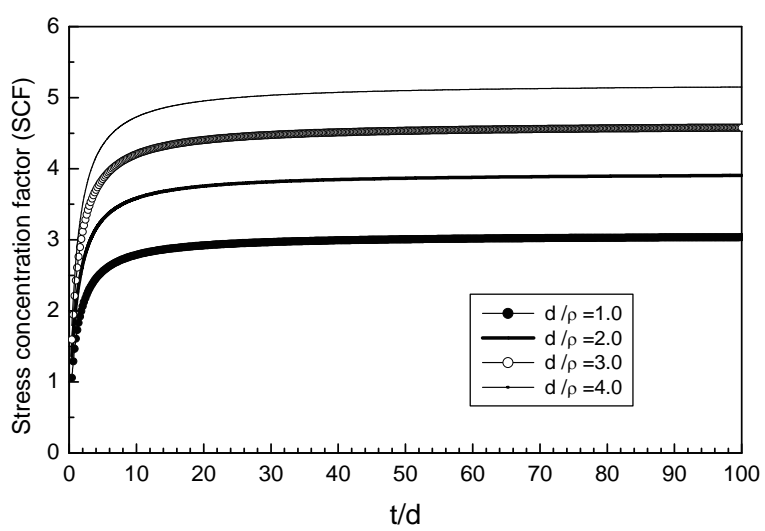

Fig. 8 V ariation of stress concentration factor with thickness of plates with semi-elliptical side notches

A s is shown in Figs. 8 and 9, the stress concentration factor and stress gradients increase with increasing the thickness. As the higher stress gradient implies a less severe situation, stress gradient plays an essential role on fatigue strength regarding the thickness of the plate.

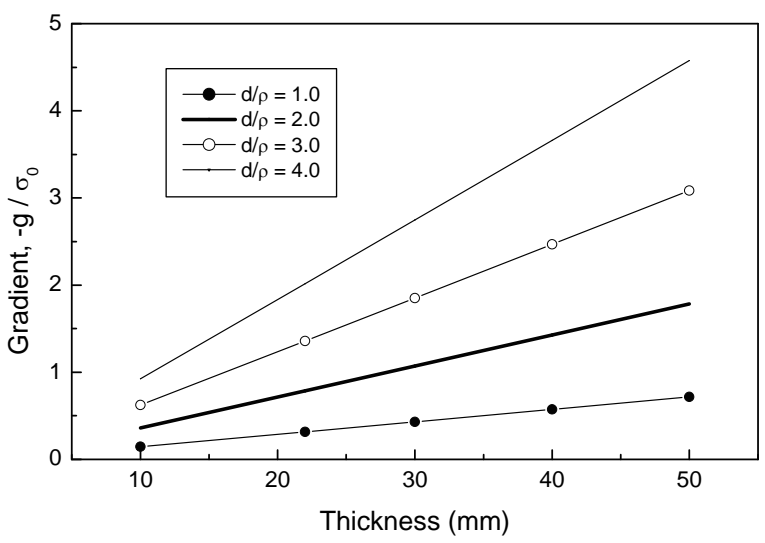

Fig. 9 V ariation of stress gradient with thickness of plates with semi-elliptical side notches

Figure 10 illustrates the stress intensity factor with crack length, and they asymptotically approach to the value for the symmetric edge cracks of length, $a$ in the rectangular plate. A the beginning of the crack growth, the stress intensity factors of thicker plates are higher than those of thinner plates, but this tendency is reversed after certain amount of crack growth. The ratio of the notch depth and notch radius is changed for five different cases $(d / \rho=0,1,2,4, \infty)$, and it is found that the results show almost the similar tendency of stress intensity factors.

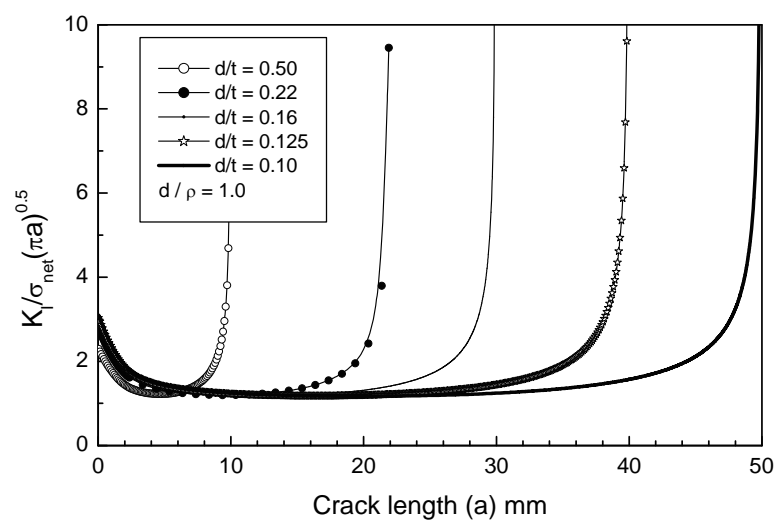

Fig. $10 \mathrm{~V}$ ariation of stress intensity factor with crack length of plates with semi-elliptical side notches $(d / \rho=1.0)$

The fatigue crack propagation lives corresponding to Fig. 10 are calculated by Eqn. (4) (Fig. 11), where the initial and the final crack sizes are assumed as, $a_{0}=0.03 \mathrm{~mm}$ and $a_{f} \simeq \mathrm{t}$, respectively. The stress range, $\Delta \sigma_{\text {net }}=100 \mathrm{MPa}$ is assumed to calculate the crack propagation life. As can be seen, the crack propagation lives do not exhibit considerable difference with respect to the variation of thickness of plates. The thickness effect of fatigue life based on the S-N approach is given by Eqn. (2), so that the relative fatigue lives to that of the plate with the reference thickness is listed in Table 1, where they do not depend on the notch sharpness. The relative fatigue life estimated by fracture mechanics is compared in Table 2 for different thickness and notch sharpness. The reference thickness is selected as $22 \mathrm{~mm}$ in this case.

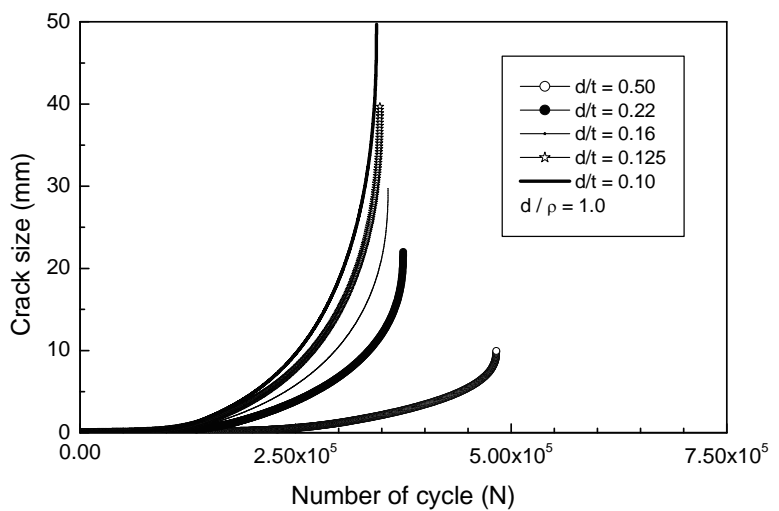

Fig. $11 \mathrm{Effect}$ of thickness on crack growth of plates with semi-elliptical side notches 
Table 1 Fatigue life $\mathrm{N}_{\mathrm{f}}$, based on the S-N approach

\begin{tabular}{cccccc}
\hline Thickness, $\mathrm{t}(\mathrm{mm})$ & 10 & $t_{B}=22$ & 30 & 40 & 50 \\
\hline $\mathrm{N}_{\mathrm{f} /} / \mathrm{N}_{\mathrm{B}}$ & 1.806 & 1.000 & 0.792 & 0.638 & 0.540 \\
\hline
\end{tabular}

Table 2 Fatigue life $N_{f}$, of plates with semi-elliptical side notches based on the Fracture $M$ echanics approach

\begin{tabular}{rrrrrrr}
\hline Thickness, $t(\mathrm{~mm})$ & 10 & $t_{B}=22$ & 30 & 40 & 50 \\
\hline \multirow{2}{*}{$\mathrm{d} / \rho=0$} & $\mathrm{~N}_{\mathrm{f}}$ & 2104320 & 2184024 & 2209460 & 2230550 & 2245420 \\
& $\mathrm{~N}_{\mathrm{f}} / \mathrm{N}_{\mathrm{B}}$ & 0.9635 & 1.0000 & 1.0116 & 1.0213 & 1.0281 \\
\hline \multirow{2}{*}{$\mathrm{d} / \rho=1$} & $\mathrm{~N}_{\mathrm{f}}$ & 482723 & 374775 & 357156 & 347781 & 343841 \\
& $\mathrm{~N}_{\mathrm{f}} / \mathrm{N}_{\mathrm{B}}$ & 1.2880 & 1.0000 & 0.9529 & 0.9279 & 0.9174 \\
\hline \multirow{2}{*}{$\mathrm{d} / \rho=2$} & $\mathrm{~N}_{\mathrm{f}}$ & 363261 & 304380 & 295817 & 292248 & 291626 \\
& $\mathrm{~N}_{\mathrm{f}} / \mathrm{N}_{\mathrm{B}}$ & 1.1934 & 1.0000 & 0.9718 & 0.9601 & 0.9580 \\
\hline \multirow{2}{*}{$\mathrm{d} / \rho=4$} & $\mathrm{~N}_{\mathrm{f}}$ & 304393 & 269854 & 265750 & 265035 & 266044 \\
& $\mathrm{~N}_{\mathrm{f}} / \mathrm{N}_{\mathrm{B}}$ & 1.1279 & 1.0000 & 0.9847 & 0.9821 & 0.9858 \\
\hline \multirow{2}{*}{$\mathrm{d} / \rho=\infty$} & $\mathrm{N}_{\mathrm{f}}$ & 261262 & 244220 & 243325 & 244671 & 246861 \\
& $\mathrm{~N}_{\mathrm{f}} / \mathrm{N}_{\mathrm{B}}$ & 1.0697 & 1.0000 & 0.9963 & 1.0018 & 1.0108 \\
\hline & & & & & &
\end{tabular}

\subsection{Butt weld}

Five different thicknesses of plates $(t=10,22,30,40$, and $50 \mathrm{~mm}$ ) are analyzed, keeping the other weld parameters constant. The stress distributions are calculated as illustrated in Fig. 12, where the coordinate $x$ is measured from the notch root to the thickness direction. In Table 3, the stress concentration factors and stress gradients are compared with the thickness, in which the stress gradients are obtained by Eqn. (9). As can be seen, the maximum stress increases with increasing the thickness. The ratios of the maximum stresses to that of the plate with the reference thickness, $t_{B}=22 \mathrm{~mm}$, are also compared in Table 3. It may be found that the thickness effect of the stress concentration factor is not so significant as compared to $1 / 4$ power law (see $3^{\text {rd }}$ and $4^{\text {th }}$ row in Table 3 ).

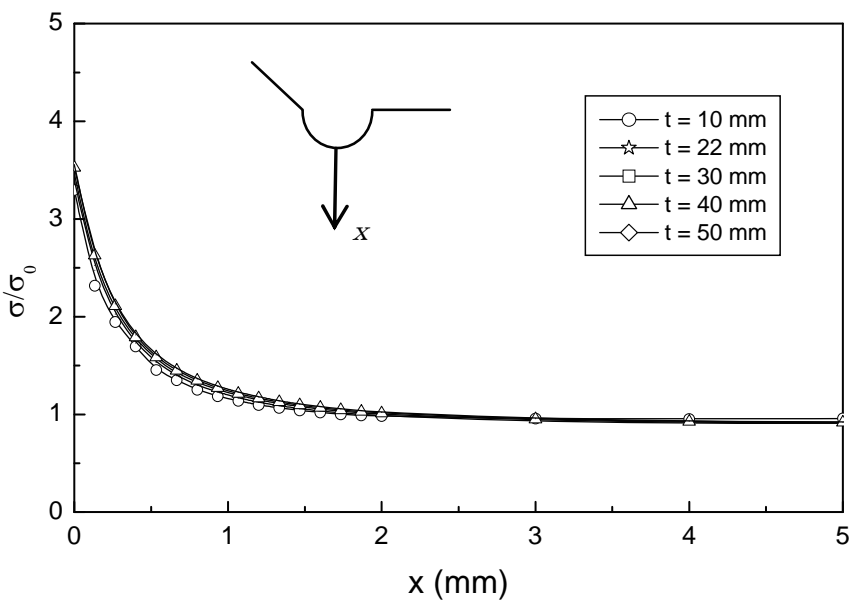

Fig. 12 Stress distribution of butt weld with undercut
Table 3 Stress concentration factor/stress gradient of butt weld with undercut

\begin{tabular}{crrrrr}
\hline Thickness, $t(\mathrm{~mm})$ & 10 & $t_{B}=22$ & 30 & 40 & 50 \\
\hline$\sigma_{\max } / \sigma_{0}$ & 3.297 & 3.396 & 3.461 & 3.527 & 3.554 \\
$-\mathrm{g} / \sigma_{0}$ & 7.683 & 7.914 & 8.064 & 8.219 & 8.280 \\
$\sigma_{\max }(t) / \sigma_{\max }\left(\mathrm{t}_{\mathrm{B}}\right)$ & 0.970 & 1.000 & 1.018 & 1.038 & 1.046 \\
$\left(\mathrm{t} / \mathrm{t}_{\mathrm{B}}\right)^{0.25}$ & 0.821 & 1.000 & 1.080 & 1.161 & 1.227 \\
\hline
\end{tabular}

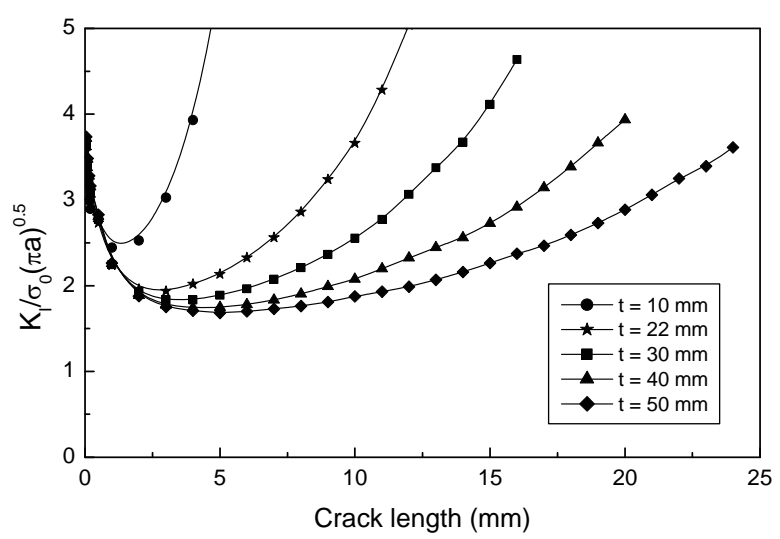

Fig. 13 Stress intensity factor of butt weld with undercut

The stress intensity factor of cracks emanating from the root of the undercut is illustrated in Fig. 13. In order to examine the detailed change of the stress intensity factors, Fig. 14 is introduced by enlarging the scale within the range, $0<x<2 \mathrm{~mm}$, where the stress distribution under intact condition is also included (right-hand-side axis). The linear stress approximation is valid in the range, $x \leq 0.2 \mathrm{~mm}$, for the butt weld with and without undercut, so that Eqn. (10) is used within this range for the evaluation of the stress intensity factor of very shallow crack at the notch root. Initially, the stress intensity factors of thicker plates are higher than those of thinner plates, but this tendency is reversed after small amount of crack growth. This reversal point will be called as the "transition point" in the subsequent discussion, and it can be understood easily from the corresponding stress distribution in the same figure.

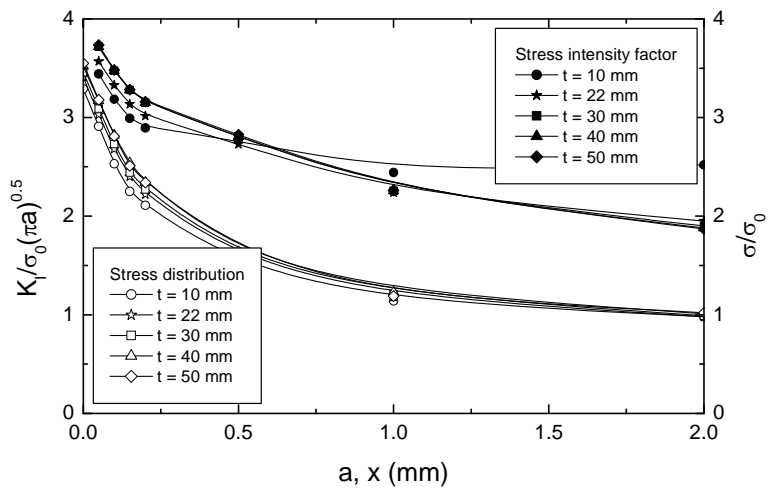

Fig. 14 Stress intensity factor and stress distribution of butt weld with undercut 
The fatigue crack propagation lives are calculated by Eqn. (4) (Fig. 15 and Table 4), where the initial crack size is assumed as, $a_{0}=0.05 \mathrm{~mm}$. Final crack lengths are taken in such a way that the stress intensity factor at the maximum load, $K_{\max }$, attains $3,000 \mathrm{~N} / \mathrm{mm}^{3 / 2}$, which may approximately correspond to the fracture toughness of structural steel. As can be seen, the crack propagation lives do not exhibit considerable difference with respect to the variation of thickness of plates.

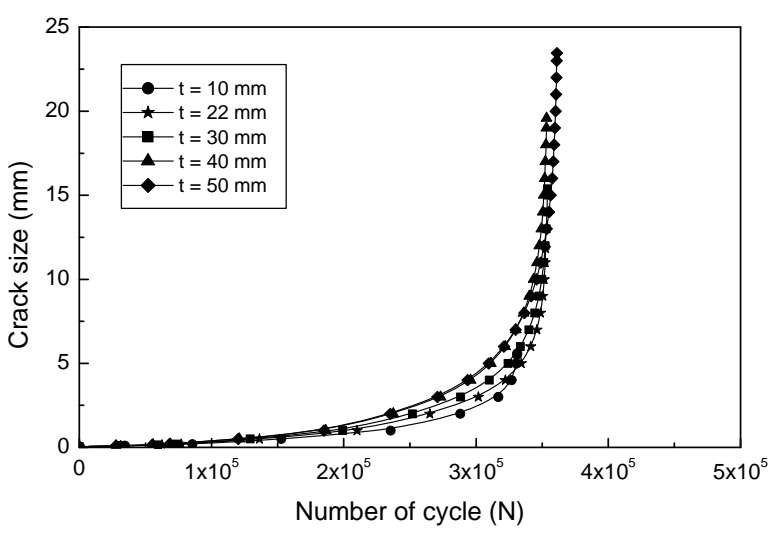

Fig. 15E ffect of thickness on crack growth for butt weld with undercut (initial crack size, $a_{0}=0.05 \mathrm{~mm}$ )

Table 4 Fatigue life, $\mathrm{N}_{\mathrm{f}}$ and the final crack length, $a_{f}$ of butt weld with undercut based on the F racture M echanics approach

\begin{tabular}{crrrrr}
\hline Thickness, $\mathrm{t}(\mathrm{mm})$ & 10 & $t_{B}=22$ & 30 & 40 & 50 \\
\hline $\mathrm{N}_{\mathrm{f}}$ & 331151 & 352617 & 354101 & 353312 & 361131 \\
$\mathrm{~N}_{\mathrm{f}} / \mathrm{N}_{\mathrm{B}}$ & 0.9391 & 1.0000 & 1.0042 & 1.0019 & 1.0241 \\
$a_{f}(\mathrm{~mm})$ & 5.60 & 11.83 & 15.38 & 19.58 & 23.45 \\
\hline
\end{tabular}

Similar calculations are carried out for the butt weld without the undercut. In Table 5, the stress concentration factors and stress gradients are compared with the thickness. Although the thickness effect of the stress concentration is more pronounced than that of the weld without undercut, it is not so significant as compared to $1 / 4$ power law. The stress intensity factors of cracks emanating from the weld toe and the stress distribution under intact condition within the range, $0<x<3 \mathrm{~mm}$ are illustrated in Fig. 16. The stress intensity factors also show the transition behavior.

Table 5 Stress concentration factor/stress gradient of butt weld without undercut

\begin{tabular}{crrrrr}
\hline Thickness, $\mathrm{t}(\mathrm{mm})$ & 10 & $t_{B}=22$ & 30 & 40 & 50 \\
\hline$\sigma_{\max } / \sigma_{0}$ & 1.888 & 2.272 & 2.381 & 2.451 & 2.485 \\
$-\mathrm{g} / \sigma_{0}$ & 4.400 & 5.295 & 5.548 & 5.711 & 5.792 \\
$\sigma_{\max }(\mathrm{t}) / \sigma_{\max }\left(\mathrm{t}_{B}\right)$ & 0.831 & 1.000 & 1.047 & 1.078 & 1.093 \\
$\left(\mathrm{t} / \mathrm{t}_{\mathrm{B}}\right)^{0.25}$ & 0.821 & 1.000 & 1.080 & 1.161 & 1.227 \\
\hline
\end{tabular}

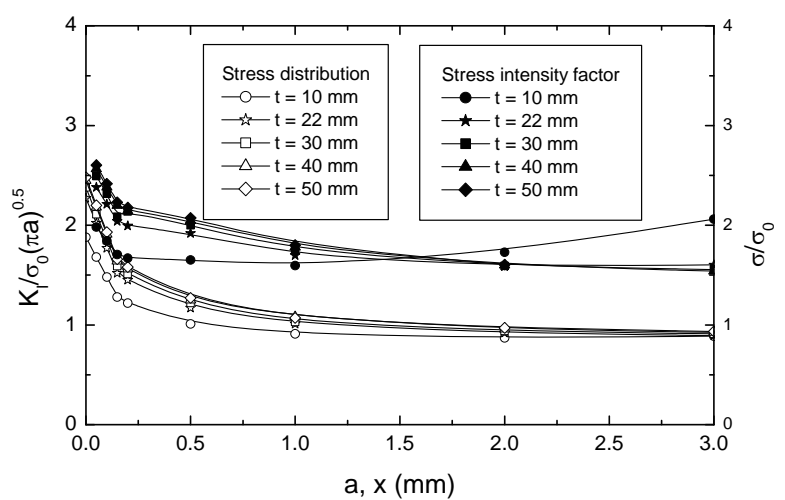

Fig. 16 Stress intensity factor and stress distribution of butt weld without undercut

The fatigue crack propagation lives are calculated and illustrated in Fig. 17 and Table 6. Since the stress concentration near the plate surface has more pronounced effect in the present case, the thickness effect of the fatigue strength has been observed, but it still is not so significant as compared to the $1 / 4$ power law in the S-N approach.

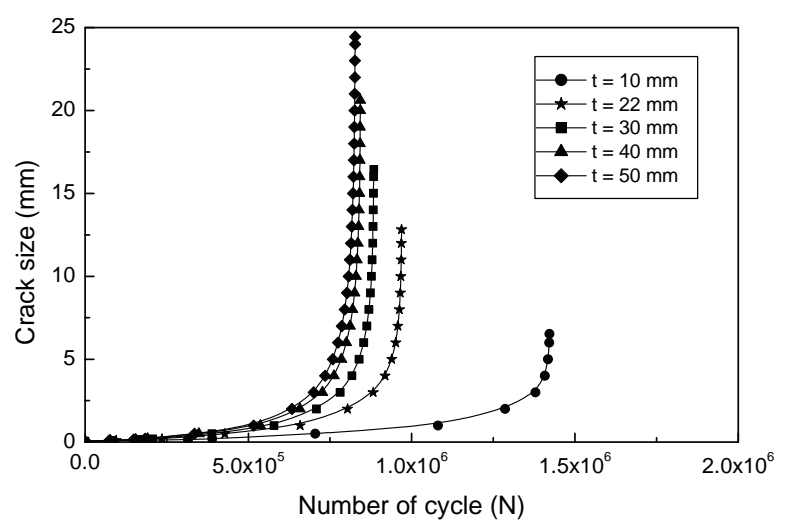

Fig. 17 Effect of thickness on crack growth for butt weld without undercut (initial crack size, $a_{0}=0.05 \mathrm{~mm}$ )

Table 6 Fatigue life, $\mathrm{N}_{\mathrm{f}}$ and the final crack length, $a_{f}$ of butt weld without undercut based on the Fracture $M$ echanics approach

\begin{tabular}{crrrrr}
\hline Thickness, $(\mathrm{mm})$ & \multicolumn{1}{c}{10} & $t_{B}=22$ & 30 & \multicolumn{1}{c}{40} & \multicolumn{1}{c}{50} \\
\hline $\mathrm{N}_{\mathrm{f}}$ & 1422050 & 969122 & 883889 & 842944 & 826823 \\
$\mathrm{~N}_{\mathrm{f}} / \mathrm{N}_{\mathrm{B}}$ & 1.4673 & 1.0000 & 0.9120 & 0.8698 & 0.8531 \\
$a_{f}(\mathrm{~mm})$ & 6.53 & 12.82 & 16.45 & 20.62 & 24.45 \\
\hline
\end{tabular}

\subsection{Fillet weld}

The stress concentration factors and the stress gradients are calculated for the fillet weld with and without undercut (see Table 7).

From Figs. 18 and 19, it is seen that at the beginning of the crack propagation the stress intensity factors of thicker plates are higher than those of thinner plate, and the transition point and transition behavior are almost similar to those of butt welds. The linear stress approximation is also made within the range, $x \leq 0.2 \mathrm{~mm}$, for fillet weld with and without undercut. From these figures, it is also found that the dominant thickness effect appears 
within the surface layer of $1.5-2.0 \mathrm{~mm}$, so that considerable effect on fatigue strength is not observed for the case of undercut with its depth $1 \mathrm{~mm}$.

Table 7 Stress concentration factor/stress gradient of fillet weld with and without undercut

\begin{tabular}{cccccc}
\hline Thickness, $\mathrm{t}(\mathrm{mm})$ & 10 & $t_{B}=22$ & 30 & 40 & 50 \\
\hline \multicolumn{7}{c}{ with undercut } \\
\hline$\sigma_{\max } / \sigma_{0}$ & 3.299 & 3.412 & 3.446 & 3.513 & 3.554 \\
$-\mathrm{g} / \sigma_{0}$ & 7.688 & 7.950 & 8.030 & 8.185 & 8.282 \\
$\sigma_{\max }(\mathrm{t}) / \sigma_{\max }\left(\mathrm{t}_{\mathrm{B}}\right)$ & 0.967 & 1.000 & 1.010 & 1.029 & 1.041 \\
$\left(\mathrm{t} / \mathrm{t}_{B}\right)^{0.25}$ & 0.821 & 1.000 & 1.080 & 1.161 & 1.227 \\
\hline \multicolumn{7}{c}{ without undercut } \\
\hline$\sigma_{\max } / \sigma_{0}$ & 2.835 & 3.418 & 3.654 & 3.785 & 3.838 \\
$-\mathrm{g} / \sigma_{0}$ & 6.605 & 7.963 & 8.513 & 8.819 & 8.942 \\
$\sigma_{\max }(\mathrm{t}) / \sigma_{\max }\left(\mathrm{t}_{B}\right)$ & 0.829 & 1.000 & 1.069 & 1.107 & 1.122 \\
$\left(\mathrm{t} / \mathrm{t}_{B}\right)^{0.25}$ & 0.821 & 1.000 & 1.080 & 1.161 & 1.227 \\
\hline
\end{tabular}

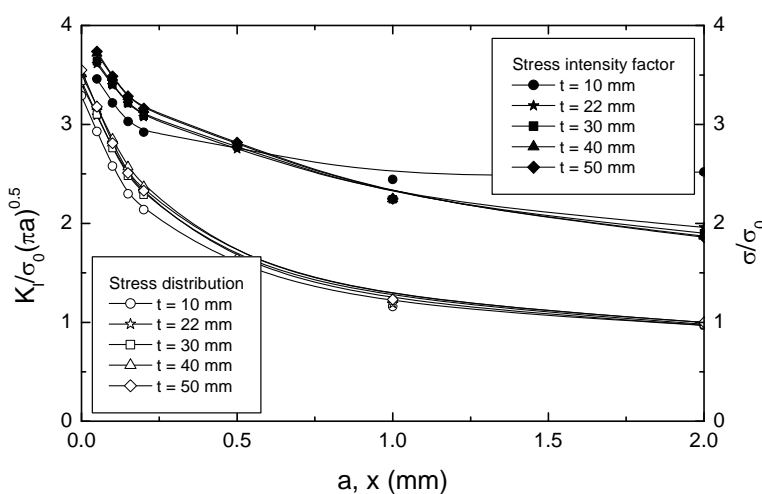

Fig. 18Stress intensity factor and stress distribution of fillet weld with undercut

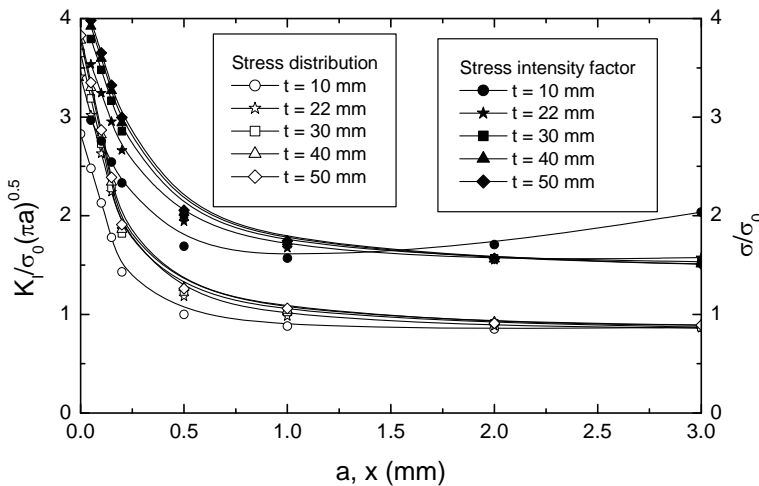

Fig. 19Stress intensity factor and stress distribution of fillet weld without undercut

The fatigue crack propagation lives are calculated by using Eqn. (4) and illustrated in Figs. 20 and 21. The final crack length is determined in the same manner as those for butt welds, and they are listed in Table 8 . Here, the crack propagation lives do not exhibit considerable difference in the case of weld with undercut, while some thickness effects are observed for the case without undercut (see also Table 8).

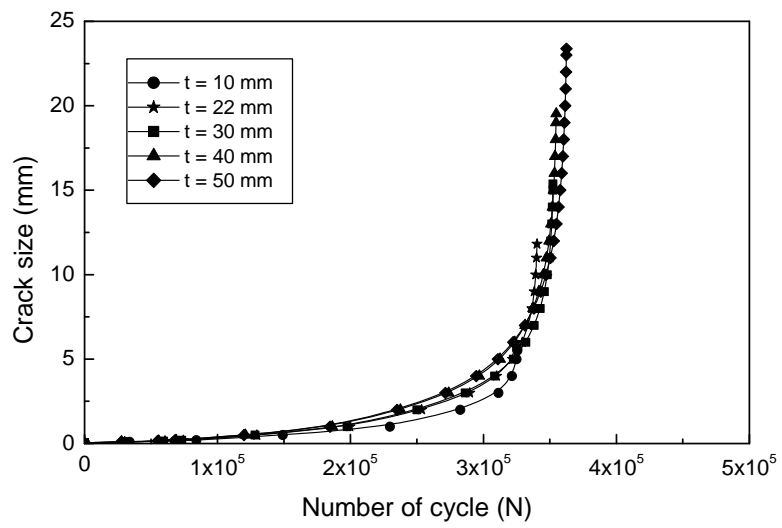

Fig. 20 Effect of thickness on crack growth for fillet weld with undercut (initial crack size, $a_{0}=0.05 \mathrm{~mm}$ )

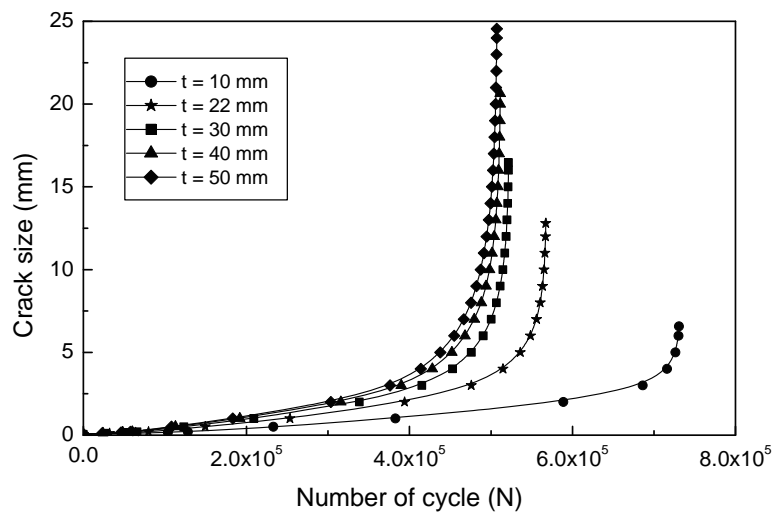

Fig. 21 Effect of thickness on crack growth for fillet weld without undercut (initial crack size, $a_{0}=0.05 \mathrm{~mm}$ )

Table 8 Fatigue life, $\mathrm{N}_{\mathrm{f}}$ and the final crack length, $a_{f}$ of fillet weld with and without undercut based on the Fracture Mechanics approach

\begin{tabular}{crrrrr}
\hline Thickness, $\mathrm{t}(\mathrm{mm})$ & 10 & $t_{B}=22$ & 30 & 40 & 50 \\
\hline \multicolumn{7}{c}{ with undercut } \\
\hline $\mathrm{N}_{\mathrm{f}}$ & 325570 & 340274 & 352359 & 354707 & 362409 \\
$\mathrm{~N}_{\mathrm{f}} / \mathrm{N}_{\mathrm{B}}$ & 0.9567 & 1.0000 & 1.0355 & 1.0424 & 1.0650 \\
$a_{f}(\mathrm{~mm})$ & 5.60 & 11.82 & 15.37 & 19.52 & 23.38 \\
\hline \multicolumn{7}{c}{ without undercut } \\
\hline $\mathrm{N}_{\mathrm{f}}$ & 730717 & 567176 & 521490 & 511400 & 507238 \\
$\mathrm{~N}_{\mathrm{f}} / \mathrm{N}_{\mathrm{B}}$ & 1.2883 & 1.0000 & 0.9194 & 0.9016 & 0.8943 \\
$a_{f}(\mathrm{~mm})$ & 6.57 & 12.80 & 16.47 & 20.63 & 24.55 \\
\hline
\end{tabular}




\section{CONCLUSIONS}

Investigations are made for the effect of plate thickness on fatigue strength of plates with semi-elliptical side notches and, butt and fillet welds with and without undercut of $1 \mathrm{~mm}$ depth, based on fracture mechanics approach, whose results are compared with the $1 / 4$ power law of the S-N approach.

Although higher stress concentration is generally observed for thicker plates, the higher stress gradient may reduce this effect after small amount of crack growth. Although the stress intensity range is initially higher for thicker plates, this tendency may be reversed after the so called transition point, so that the thickness effect could not be so pronounced. Especially, in the present illustrative examples it is found that the thickness effect affects the stress distribution within a very thin surface layer, so that the effects of surface undulation such as undercuts or corrosion pits may also reduce the thickness effect. The welding residual stress is certainly another factor of thickness effect on fatigue strength to be studied in the near future.

\section{ACK NOWLEDGMENT}

This work is supported by the Grand-in-Aid for Scientific Research (A(2)22246109) from Japanese Society for the Promotion of Science to Y okohama National University. The first author is supported by scholarship from the J apanese G overnment. The authors are grateful for their supports.

\section{REFERENCES}

1) Fukuoka T. and Mochizuki K.: Effect of plate thickness on fatigue strength of typical welded joints for a ship structure, International Institute of Welding, X III-2333-10, 2010.

2) Gurney T.R.: The influence of thickness on fatigue of welded joints-10years on (a review of B ritish work), Proc. $8^{\text {th }}$ Int. Conf on offshore M ech. and A rctic Eng., Vol. III, The Hague, The N etherlands, M arch 19-23, 1989, pp. 1-8.

3) Gurney, T.R.: Theoretical analysis of the influence of toe defects on the fatigue strength of fillet welded joints, W elding Institute Research Report, 1977, 32/1977/E.

4) IACS: Common Structural Rules for bulk carriers, J uly 2009.

5) IACS: Common Structural Rules for double hull oil tankers, July 2010.

6) ISSC Committee III.2: Fatigue and Fracture, Proc. of 17th International Ship and Offshore Structures Congress, V ol. 1, 2009, pp. 475-585.

7) Gurney T. R.: Some comments on fatigue design rules for offshore structures, Proc. $2^{\text {nd }}$ Int. Symp on Integrity of Offshore Struct, Essex, England, 1981, pp. 219-234.

8) $Y$ amamoto $Y$., Sumi $Y$. and A o K .: Stress intensity factors of crack emanating from semi-elliptical side notches in plates, Int J ournal of fracture 10, 1973, pp. 593-595.

9) B enthem J. P. and K oiter W. T .: A symptotic approximation to crack problems, in methods of analysis and solutions of cracks problems, Noordhoff, 1973, pp. 131-178. 